\title{
In Response
}

We appreciate the letter by Dr Candido and colleagues. We are pleased that they avoid the 'safe' triangle, as well. Both of our papers have endorsed a posterolateral approach to the transforaminal epidural steroid injection (TFESI) to avoid the 'safe' triangle. In Dr. Candido's paper, his posterolateral TFESI approach places a needle higher up along the superior articular process (SAP); we advocate placing the needle lower down along the SAP, to target Kambin's triangle.

In his posterolateral TFESI technique there is a risk of contacting the nerve root and in our technique, there is a risk of contacting the disk. At their respectively rare extremes, his technique carries a remote risk of nerve injury (as does the 'safe' triangle approach); and our technique carries a remote risk of discitis. Both of these complications, however, have less morbidity and better treatment outcomes when compared to paraplegia. Paraplegia is immediate and typically irreversible.

We are encouraged that Dr. Candido, another expert in interventional pain management, has not only abandoned the 'safe' triangle TFESI to improve patient safety, but has jumped ship even further-in revisiting the interlaminar epidural steroid injection (ILESI).

In Dr. Candido's paper, anterior contrast spread (as a surrogate for targeting the ventral epidual space) was more reliably demonstrated with his paramedian ILESI technique as opposed to his posterolateral TFESI approach. However, when you compare his figure 3 (posterolateral TFESI) versus his figure 5 (paramedian ILESI), contrast spreads into the foramen and ventral epidural space more consistently with the TFESI. Also, 
a $5 \mathrm{ml}$ volume was required for the ILESIs and TFESIs in his paper. While we understand the decision making involved in larger volume epidural steroid injections for therapeutic reasons, many practitioners use smaller volumes and prefer target specificity. Many of these practitioners will continue to criticize non-TFESI routes because of the need for larger volumes; lack of target specificity; and dilution of the steroids. We anticipate these practitioners will continue to practice TFESIs, despite the comparability in outcomes demonstrated in Dr. Candido's paper.

With respect to complications, ILESIs are associated with remote, but significant risks and morbidity. Post dural puncture headaches, epidural abscesses, epidural hematomas, arachnoiditis, spinal cord/nerve root injuries, and subdural injections are reported complications. The diversity of these complications poses a challenge in pinpointing the exact problem. The practitioner is faced with a 'rolodex' of possible complications--this can delay diagnosis and timely treatment. The Kambin triangle TFESI winnows down the number of probable complications, relative to the ILESI. This facilitates early detection of a complication. Early and accurate diagnosis of a complication is imperative to patient safety.

Innovations in the targeted epidural delivery of steroids may require validation in the form of randomized controlled trials for each individual variance, as suggested by Dr. Candido. We do not believe this is necessary. One can imagine two practitioners debating whether to use a $22 \mathrm{~g}$ vs. a $25 \mathrm{~g}$ spinal needle for a TFESI-it would be very easy for a third party to demand a clinical trial to decide upon the 'best' needle. Each variance in these techniques, e.g., volume of delivery, type of needle, type of corticosteroid, etc.., doesn't necessarily warrant a repeat clinical trial. Furthermore, contrast spread patterns, between 'unsafe' triangle TFESIs, Kambin triangle TFESIs, and paramedian ILESIs would need to be compared in an individual patient, for relevance in that particular patient; even then, the contrast spread pattern could change with repetition of the identical procedure in that very same patient. Existing systematic reviews have demonstrated the ef- ficacy of the transforaminal and interlaminar route. The primary focus, when evaluating a 'new' TFESI or ILESI approach, should be directed towards patient safety and reproducibility--not on outcomes.

Overall, we applaud Dr Candido's equal concern about the 'safe' triangle. His paper underscores the legitimate fears practitioners have about safe triangle TFESIs. Dr. Candido has opted for controllable risk, but reduced target specificity and reduced selectivity. The 'safe' triangle poses the uncontrollable ('Black Swan') and untreatable risk of paraplegia. His publication and our publication are advising alternate strategies to the dangerous safe triangle technique. This is common ground.

We have received a number of favorable comments since the publication of our manuscript. We are encouraged that this Kambin triangle approach has been utilized by other expert interventionalists, vis a vis other appellations. Dr. Finch has been using this technique in Australia. This underscores the global need to advocate for patient safety. Collectively, we call on all practitioners to avoid the 'unsafe' triangle TFESI and to no longer teach this technique to future interventionalists.

\author{
Scott E. Glaser, MD \\ Pain Specialists of Greater Chicago \\ 7055 High Grove Blvd. Ste. 100 \\ Burr Ridge, IL 60527 \\ E-mail: sglaser@painchicago.com \\ Rinoo V. Shah, MD \\ Guthrie Clinic \\ Interventional Pain Management \\ 31 Arnot Road \\ Horseheads, New York 14845 \\ E-mail: rinoo_shah@yahoo.com \\ Philip M. Finch, MD \\ Perth Pain Management Centre \\ South Perth, Australia \\ E-mail: jean.finch@iinet.net.au
}

\section{References}

1. Candido KD, Raghavendra MS, Chinthagada M, Badiee S, Trepashko DW. A prospective evaluation of iodinated contrast flow patterns with fluoro- scopically guided lumbar epidural steroid injections: the lateral parasagittal interlaminar epidural approach versus the transforaminal epidural approach.
Anesth Analg 2008; 106:638-644.

2. Glaser SE, Shah RV. Root cause analysis of paraplegia following transforaminal epidural steroid injections: the 'unsafe' 
triangle. Pain Physician 2010; 13:237244.

3. Manchikanti L, Boswell MV, Datta S, Fellows B, Abdi S, Singh V, Benyamin RM, Falco FJ, Helm S, Hayek SM, Smith HS;
ASIPP. Comprehensive review of therapeutic interventions in managing chronic spinal pain. Pain Physician 2009;12: E123-198.

4. Abdi S, Datta S, Trescot AM, Schul- tz DM, Adlaka R, Atluri SL, Smith HS, Manchikanti L. Epidural steroids in

the management of chronic spinal pain: a systematic review. Pain Physician 2007;10:185-212. 